\title{
M2-TYPE MACROPHAGES IN TUMOUR MICROENVIRONMENT AS PROGNOSTIC MARKERS IN WOMEN WITH BREAST CANCER
}

Luciana V Q Labre1, Vera A Saddi ${ }^{2,3,4}$, Megmar A S Carneiro', Aline C Batista ${ }^{5}$, Diego A C Arantes ${ }^{5}$, Jessica E P Ramos' ${ }^{2,3,4}$, Erika C Aquino1, Silvia H Rabelo-Santos ${ }^{1,6}$

IInstituto de Patologia Tropical e Saúde Pública, Universidade Federal de Goiás - Goiânia (GO), Brazil. ${ }^{2}$ Programa de Pós-graduação em Ciências da Saúde, Universidade Federal de Goiás - Goiânia (GO), Brazil. ${ }^{3}$ Laboratório de Diversidade Genética, Pontifícia Universidade Católica de Goiás - Goiânia (GO), Brazil. ${ }^{4}$ Laboratório de Oncogenética e Radiobiologia, Hospital Araújo Jorge, Associação de Combate ao Câncer em Goiás Goiânia (GO), Brazil.

${ }^{5}$ Faculdade de Odontologia, Universidade Federal de Goiás - Goiânia (GO), Brazil.

${ }^{6}$ Faculdade de Farmácia, Universidade Federal de Goiás - Goiânia (GO), Brazil.

The objective of this study was to assess the prognostic value of tumour-associated macrophages (TAMs) with a possible M2-type macrophage phenotype (CD163+) in women with breast cancer. Cases selected among the records of anatomopathological examinations carried out at a reference center for cancer treatment. Inclusion of confirmed cases of invasive ductal carcinoma with clinical follow-up for 5 years. The laminas were subjected to immunihistochemical analysis with monoclonal antibody TAMs like M2-type (CD163). For the statistical analyses, the cases were classified according to the mean value of cell tagging as low infiltration or high infiltration. High levels of TAMs (CD163+) were significantly correlated with distant metastases, lack of receptors estrogen (ER) or progesterone receptors (PR) and triple-negative breast cancer (TNBC). A high number of CD163+ cells was a strong independent prognostic factor. High infiltration of CD163+ emerged as a strong independent prognostic factor. Additional markers able to identify patients with more aggressive types of breast cancer may help predict a poorer prognosis. 